\title{
Reliability Based Maintenance in Hydropower: A Case Study of Bijaypur-I Small Hydropower Plant
}

\author{
Rajan Sharma*,1 and Nawaraj Bhattarai ${ }^{2}$ \\ ${ }^{1}$ Department of Industrial Engineering, Thapathali Campus, Institute of Engineering, \\ Tribhuvan University, Kathmandu, Nepal \\ ${ }^{2}$ Department of Mechanical Engineering, Pulchowk Campus, Institute of Engineering, \\ Tribhuvan University, Kathmandu, Nepal \\ *Corresponding Email: rajan31sharma@gmail.com
}

\begin{abstract}
Reliability engineering is emerging field which provides a tools to ensure the system is capable to deliver reliable product and service to the customer. Electricity is one of the most important human needs in this modern age. So reliability of such facilities plays important role in the quality of life and the economy of the county. Hydropower is one of the main source of energy in Nepal, whose reliability plays important role to successful transaction of traditional fuel to electricity to ensure the targeted energy consumption by government of Nepal in fifteenth five year plan. So this paper foster the way of improving the reliability of hydropower plant to ensure the reliability of power supply in National grid. As the study carried out in Bijayapur-I small Hydropower plant, the reliability and availability found as 0.876 and 0.793 only and insufficient flow seems the major contribution to decrease reliability as scheduled outage, whereby problem in turbine section plays important role to reduce the reliability in the electromechanical system of the plant whose contribution in reliability and availability is $79 \%$ so any failure in turbine section adversely affects the performance of plant. Due to this the maintenance strategy should be focused on turbine section. And the study recommended to increase the frequency of flushing of radial filter of cooling system, redundancy in filter system can increase the reliability, use of cyclone separator to separate the dissolved limestone and dissolved sand is the another option, and to use close loop cooling system instead of open system.
\end{abstract}

Keywords: Availability, Critical Assets, Electromechanical System, Hydropower, Reliability, Strategy

\section{INTRODUCTION}

Maintenance is any activities that are intended to preserve the function of the assets not the assets so that we can get reliable output for the long period of time [1]. Reliability engineering is a very fast growing and very important field in consumer and capital goods and service industries. It provides the theoretical and practical tools to ensure that the product and services that deliver by the system is reliable by 
specifying the probability and capability of systems can perform their required functions in specified environments for the desired period of operation without failure. And it provides feedback to engineering, manufacturing, quality control, and service for improvements and necessary corrective actions.

Electricity is one of the most important human needs in this modern age. So reliability of such facilities plays important role in the quality of life and the economy of the county. Uncertain power outage due to the problem in power plant may question marks to the power supplier and also losses to the power producer. The reliability of the services can only be fulfilled when the machinery parts are in well condition i.e. if they are reliable.

Government of Nepal has plan to increase the rate of per person energy consumption from $198 \mathrm{kWhr}$ to $700 \mathrm{kWhr}$ at the end of 15th five year plan [2]. Hydropower is a main source of energy in Nepal, as it is estimated about $83000 \mathrm{MW}$ and its technically and economically feasible potential is about $45000 \mathrm{MW}$ and $42000 \mathrm{MW}$ respectively from more than 6000 rivers of Nepal [3]. Government plan will be successful only if the consumer which are using traditional fuels such as firewood to the another form of energy called electricity which have large range of utilities and application. A research has show that Consumers are willing to have a sustainable energy transition from traditional fuels to electricity and willing to pay $19 \%$ to $25 \%$ of the existing average monthly bill for reliable electricity supply [4]. And reliable electricity supply is possible only when the source is reliable. To ensure quality and reliable operation of the equipment, to maximize availability of equipment with least number of shut down and Eradication / non repetition of operational problems in hydropower Planned maintenance is required [5] Reliability Based Maintenance is a technique to develop the strategies to increase the reliability and availability of the system. It provides feedback to the Operation and Maintenance team, Engineering and the management regarding the reliability of the plant. It also develops Preventive Maintenance which depends on the theory of preventing potential failure which could have serious consequences or which have more share to decrease the availability and reliability of the plant. It recognizes that design and operation of each equipment differs and therefore probability of failure also differ from equipment to equipment. So in this system a factor reliability is used to access when the component near to failure and should be replace with the approach to eliminate more costly unscheduled maintenance and to minimize preventive maintenance.

\section{Methods and Material}

Aiming to run the applicability of the methodology proposed in this paper, it is necessary to define a hydroelectric plant that will be taken as the basis of analysis in order to complete characterize their systems, allowing the application of Fault Tree Analysis, which forms the basis for a future implementation of Reliability based maintenance policies and asset management techniques. This study is based on the case study of Bijayapur-I Small Hydropower Project (BSHP-I). It is a multipurpose, run of the river type, 4.5 MW small hydropower project located at Pokhara-Lekhnath Metropolitan city of Gandaki Provenance. It uses water of Bijayapur Khola and Sheti Irrigation Drainage. Which is $2 \mathrm{~km}$ from the prithivi Highway. With rated Design head $65.4 \mathrm{~m}$ and discharge $8.3 \mathrm{~m} 3 / \mathrm{s}$ is operating since Bhadra 9, 2069 BS. BSHP-I was developed by Bhagabati Hydropower Company (p) ltd, with the financed of Rastriya Banijya Bank, Nabil Bank and Napal Bank Ltd. It has two units of horizontal shaft Francis turbines to generate electricity.

The method adopted in this study is shown in figure below. Marchov three state model was adopted to define the state i.e up state and down state in hydropower which classifies the down state into two categories, Scheduled Outage and Forced Outage. Forced outage includes all of the failure due to the failure in Electromechanical component in hydropower and Scheduled outage includes the failure of plant due to insufficient flow, flood, system error in the NEA, Problem in the grid transmission line and 
planned shutdown for the inspection and maintenance [6]. Fault tree analysis technique was used to identify the critical assets and computational technique of fault tree analysis was used to calculate the reliability and availability of the plant. The failure rate and mean down time of the top event of fault tree was computed by using the relation

$$
\lambda=\lambda 1+\lambda 2+\ldots \ldots \ldots
$$

and

$$
\mathrm{MDT}=\frac{\lambda 1 * M D T 1+\lambda 2 * M D T 2+\cdots \cdots \cdots}{\lambda 1+\lambda 2+\cdots \ldots \cdots \cdots \cdots}
$$

For OR gate i.e for series system

$$
\begin{aligned}
& \lambda=\lambda 1 * \lambda 2 *(\text { MDT1 } 1 \text { MDT2 }) \\
& \text { and } \frac{1}{M D T}=\frac{1}{M D T 1}+\frac{1}{M D T 2}+\ldots \ldots \ldots
\end{aligned}
$$

for event connected with AND gate i.e for parallel system.

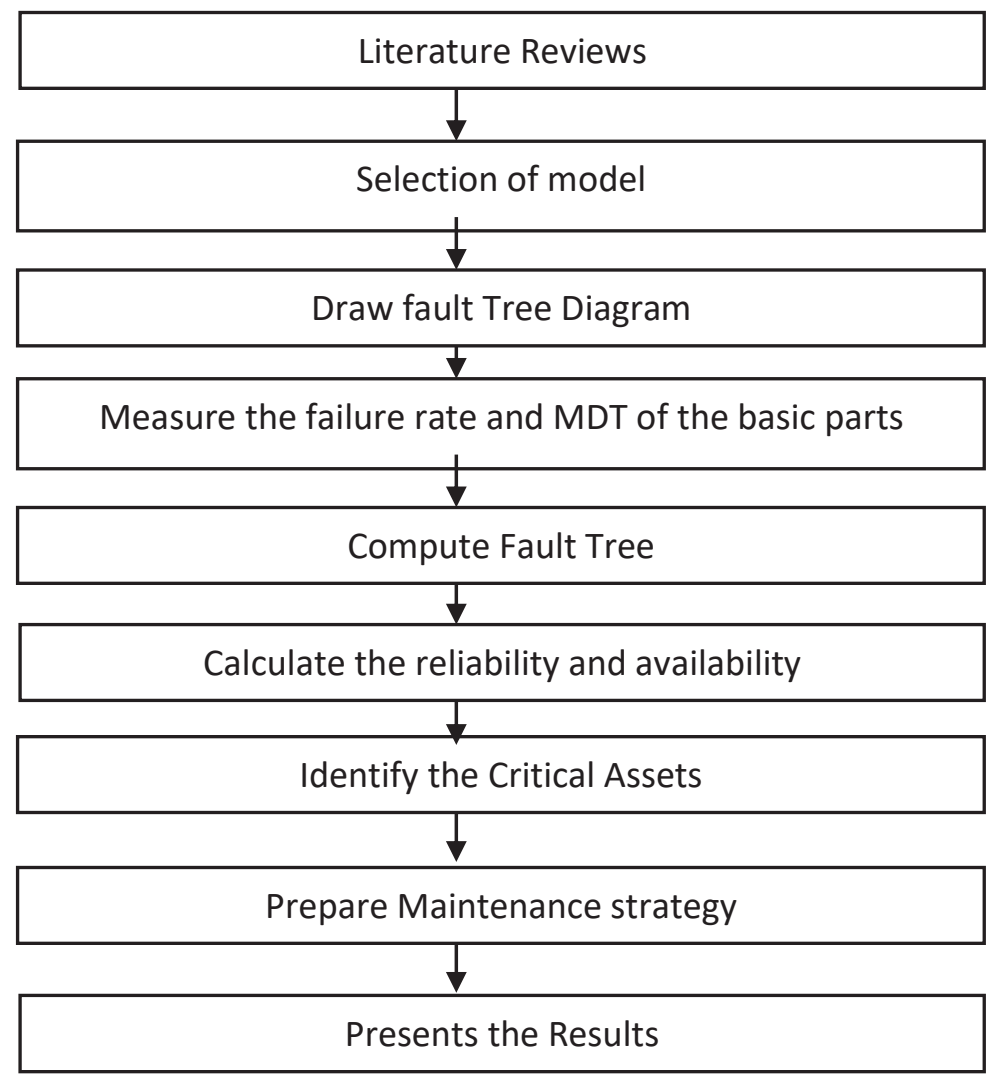

Figure 1: Research Framework [13] 
The failure rate and downtime of each component, section and overall plant is calculated by using formula eq. 1 to eq. 4 . And the reliability is calculated by using eq.5.

$$
\begin{aligned}
& R(t)=1-\int_{0}^{t} f(t) d t=e^{-\lambda t} \\
& \mathrm{AI}=\mu /(\lambda+\mu)
\end{aligned}
$$

Where: $\quad \lambda=$ Failure rate $=1 / \mathrm{MTBF}$

$$
\mu=\text { Repair rate }=1 / \mathrm{MTTR}
$$

The data for analysis was taken from log sheet maintained from F/Y 2069/70 to F/Y 2075/76 at BSHPI and the field survey of BSHP-I.

\section{RESULTS AND DISCUSSION}

\subsection{RESULTS}

The failure data from the log sheet of BSHP-I were analyse through the Analytical Hierarchical Based fault tree analysis method. Firstly the fault tree of the BSHP-I was constructed with the help of failure data, interaction with the operation in-charge of BSHP-I and different literatures related to operation and maintenance of hydropower. The reliability and availability of Unit -I and unit-II of BSHP-I is shown in figure, which shows that reliability and availability of BSHP-I is only 0.876 and 0.793 which is very poor as compared to Sunkoshi Hydropower Plant. As the reliability and availability of sunkoshi hydropower plant found as 0.997 and 0.899 [9]. Also it is clearly visualize from the figure-1 that the reliability and availability of unit-I is much less than Unit-II.

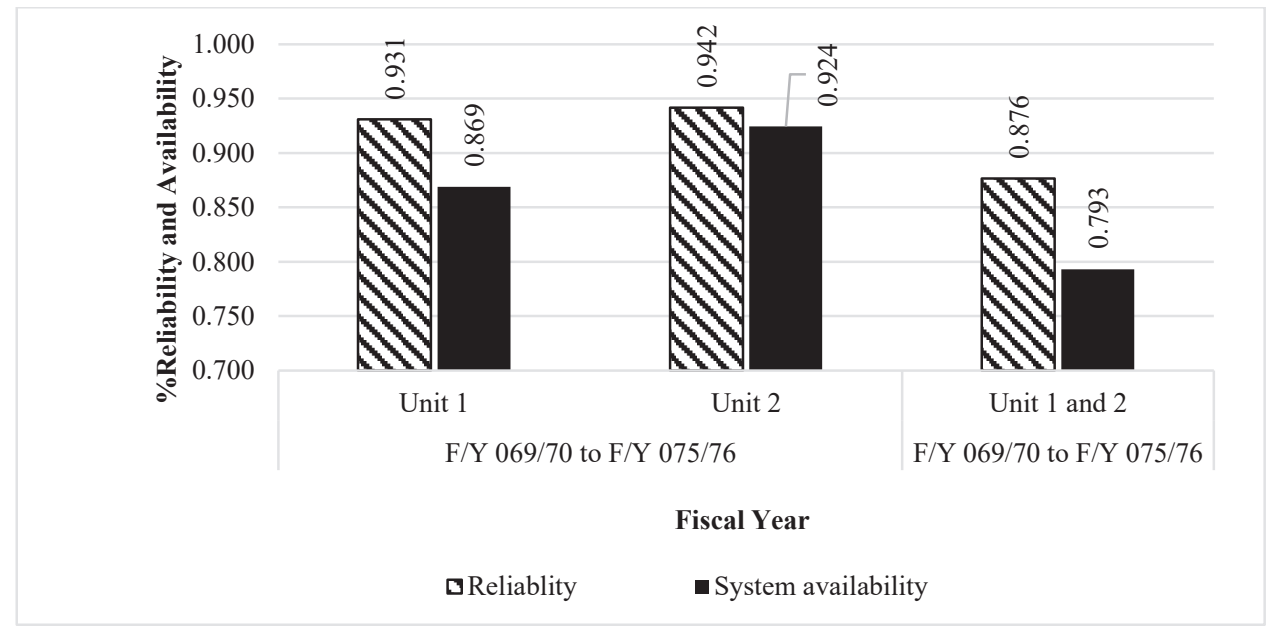

Figure 2: Reliability and Availability analysis of BSHP-I from 2069/70 to F/Y 075/76

As from the analysis, it is found that the contribution of Scheduled outage is much greater than Forced outage in the reliability and availability of BSHP-I. Scheduled outage includes all of the planned shut down and the shut down due to other failure or activities other than the electromechanical failure. In BSHP-I in most of the case insufficient flow is the main reason. And other two factor preventive 
maintenance and Reserve/system failure have less contribution as shown in figure below. And to increase the reliability of the BSHP-I the management has to work out through it. As we are concerning about Reliability based maintenance which focuses on the reliability concerned assets. After the analysis it is found that Turbine section failure contribute $79 \%$ in the reduction of availability and reliability of the BSHP-I. Which means that the critical assest should be in Turbine section as shown in figure below. After analysing the failure data of turbine section, it is found that Cooling system failure plays important role in failure in turbine section which shows that cooling system is the critical assets of the BSHP-I.

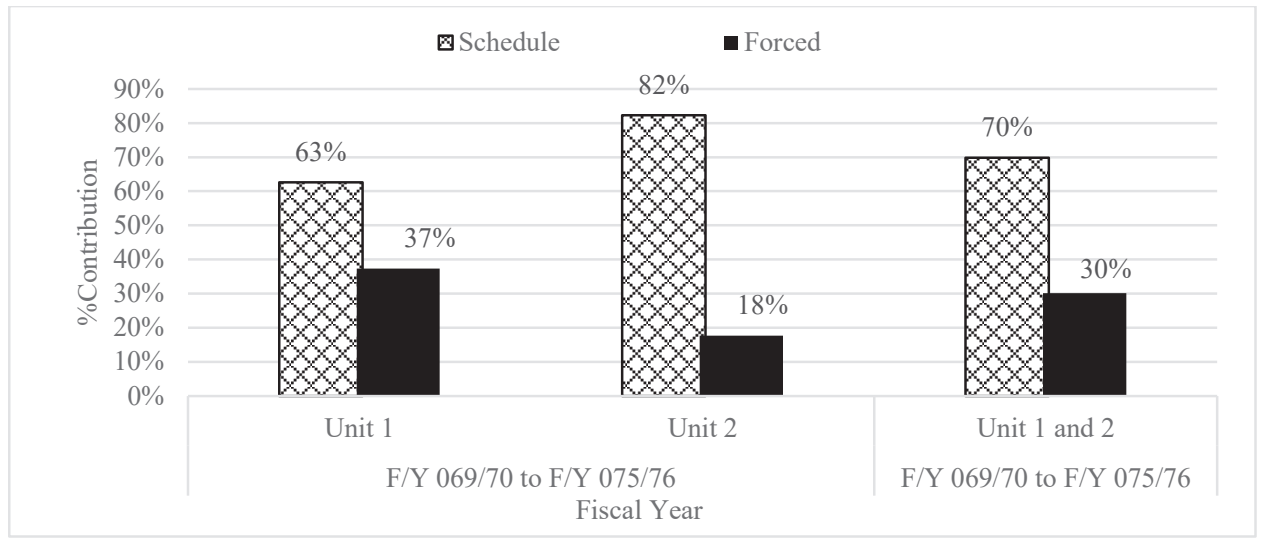

Figure 3: Contribution of Forced outage and scheduled Outage in BSHP-I

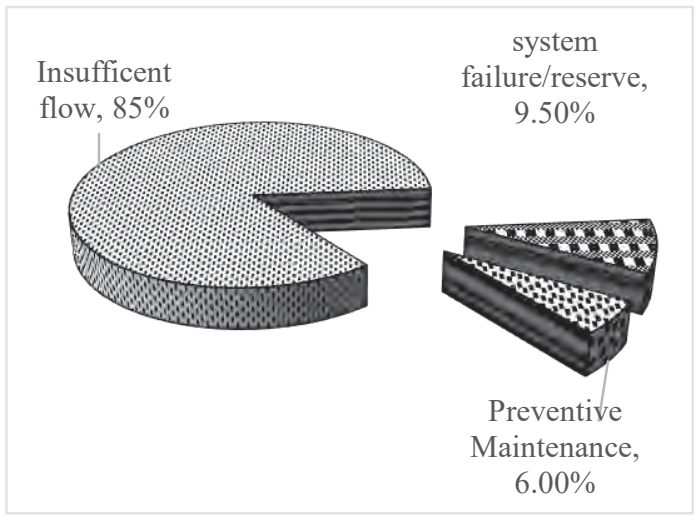

Figure 4: Contribution in Scheduled Outage of BSHP-I

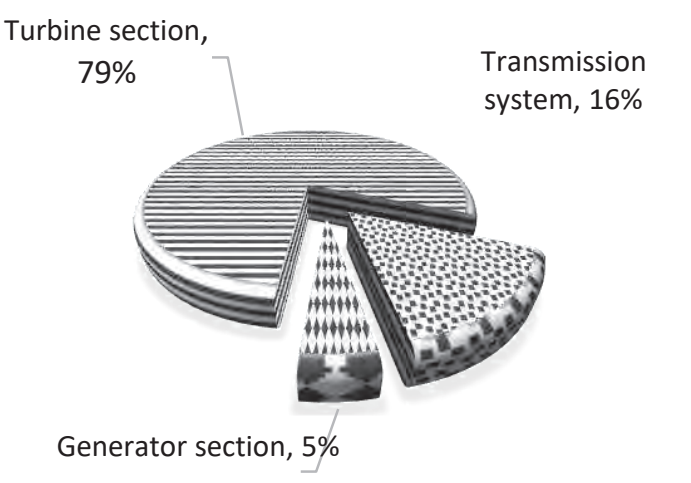

Figure 5: Contribution In Forced Outage of BSHP-I 


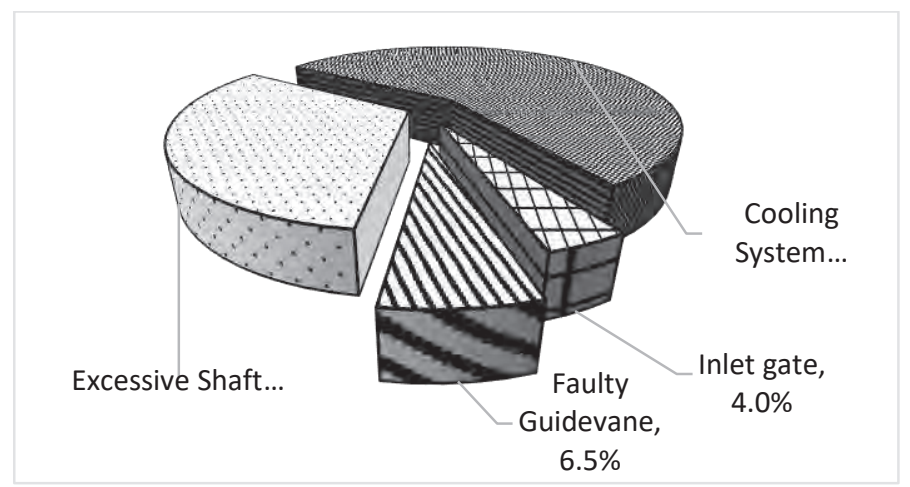

Figure 6: Contribution in Turbine Section failure

From the study of the failure data, it is found that $57.2 \%$ of problem in turbine section is due to frequent warning to stop the plant due to excessive heat in the shaft bearing and guide vane section. And this is due to the cooling system failure and after the root cause analysis the main cause of cooling system failure is jam of tube filter due to the lime stone.

\subsection{DISCUSSION}

As BSHP-I is multipurpose Hydropower project, which use drainage of irrigation project to generate electricity though some addition from Bijayapur khola, however the water from Bijayapur khola is used for irrigation purpose in dry season in Bijayapur area. The irrigation canal cross the pokhara city so any small disputes in local community disturb the flow of water in irrigation cannel. And also if any problem in Sheti fewa hydropower also affects the water flow in irrigation cannel, which is the main causes of scheduled outage. Moreover in Forced outage despite of Generating section and Transmission system Turbine section has great contribution in the reliability of the plant. The result shows that cooling system of turbine section has major contribution in the failure in turbine section. The main reason behind the failure in cooling system is the failure in filter. As BSHP-I uses radial water filter for cooling system. Since Sheti river flows in the soft land basin and carry the mixture of lime stone. Which cannot be desand by the desender of sheti hydropower and BSHP-I, which create problem in turbine section and cooling section. Formation of layer of limestone in radial filter cause blockage to flow water in the cooling system, and also deposition of layer in runner cause the failure in the bearing, jam of runner etc. so to solve these problem the study purposed some solution as per the prior research related to these problem.

\section{CONCLUSION AND RECOMMENDATIONS}

\subsection{CONCLUSION}

From these findings and discussion it can be concluded that reliability and availability of the BSHP-I is found 0.876 and 0.793 , which shows that the performance of BSHP-I is very poor as compared to sunkoshi hydropower. And most of the time it suffers from insufficient flow problem which is due to nature i.e. Multipurpose and surround by many vestigial interest group. Beside that there are many outage other than scheduled outage in plant that contribute to reduce the performance of the plant. To enhance the performance of the system it is necessary to idlentify the area which have more contribution in reliability. In such cases Analytical hierarchical based fault tree analysis method can be helpful to calculate the reliability and availability of the plant and also helpful to identify the most contributing factor so that we can prepare the strategy which helps to uplift the reliability and availability of the plant and also feedback to design engineer to consider these factor in the new design. 


\subsection{RECOMMENDATIONS}

Following strategies are recommended to improve the reliability and availability of the plant:

Redundancy: From the point of view of economy, ease of maintenance, and ease of adaptation of existing equipment, it would be desirable to make the largest possible units redundant [8]. In this case if we add a parallel panel of filter, the reliability of the cooling system can be improved form 0.989 to 0.999 and availability from 0.953 to 0.997 .

Frequency of flushing: As reliability of the cooling system is 0.989 for 24 hours. If the flushing frequency is increased to 3 times a day the reliability will increased to 0.998 and availability improved to 0.989

Cyclone Separator: In power station victimized by silts water, frequent choking of strainers has been experienced requiring their cleaning every week and in some situations even every day. Solution lies in incorporating additionally the cyclone separators on the discharge side of the cooling water pumps the cyclone separators draw water through tangential slots and accelerate the filtration process taking advantage of the centrifugal force. It is claimed that they can arrest $90 \%$ of silt particles of size as small as 74 microns. [9]

Closed circuit cooling water system: In arrange to dispense with the unfavourable impact of residue, a closed circuit cooling framework could be considered, consisting of a water tank of adequate capacity, heat exchangers and circulating pumps. Initial filling and make up water can be drawn from shaft sealing water supply, to keep circulating in a closed cycle through coolers and heat exchangers. Closed circuit frameworks could be temperate in the long run since they can be outlined to consume less power compared to that required for pumping water from the tail race or indeed compared to the misfortune of generation related with penstock tapping. [9] Also this issue can also be overcome by presenting a near close loop together with an open loop circuit of cooling water supply which passes through a Tubular Heat Exchanger directly submerged into Draft Tube water where heat exchange might takes place. [12]

\section{ACKNOWLEDGEMENT}

First of all we would like to thanks Department of Mechanical Engineering at IOE Pulchowk Campus for providing this marvellous opportunity to work on this paper. And express our immense gratitude to Er. Subash Bhandari Assistant manager of Bijaypur-I Hydropower plant for introducing with such enthusiastic working environment and providing us with various data and information. We also like to show appreciation to Er. Rajendra Prasad Bhatta, Er. Sudan Neupane, Er. Sushant Raj Giri and Er. Bishworam Parajuli for their assistance in analyzing the data and various support during this study.

\section{REFERENCES}

[1] L. Higgins and R. Mobley, Maintenance Engineering Handbook (Sixth ed), United States of America: The Mc_Graw Hill Companies, 2001.

[2] National Planning Commission , "Concept paper of 15th five year plan," Government of Nepal, Kathmandu, Nepal, 2019. 
[3] Nepal Electricity Authority, "NEA annual report - 2076," Nepal Electricity Authority, Kathmandu, 2076.

[4] T. H. Meles, "Power Outages, Increasing Block Tariffs and Billing Knowledge," in Department of Economics, School of Business, University of Gothenburg, Sweden, 2017.

[5] Alternate Hydro Electric Centre, "Guidelines for small hydro Development Roorkee," Government of India, Delhi, 2011.

[6] A. a. S. N. majeed, "Availability adn Reliability Evaluation of Dokan Hydro Power Station,2006," in IEEE/PES Transimission and Distribution Conference and Exposition, Latin America, 2006.

[7] D. D. J. Smith, Reliablity, Maintainability and Risk, Sixth edition 2001 ed., London, England: Butterworth-Heinemann, 2001, pp. 104-105.

[8] S. Chaturvedi, "Reliability Model and Failure Parameter Grouping for Maintenance Analysis of Hydro Power Plants: A Review," International Journal of Advance Research in Science and Engineering, pp. 957-965, 2018.

[9] D. Sapkota, T. R. Bajracharya and M. C. Luintel, "Reliability and Availability Evaluation of Sunkoshi Hydro Power Station," in IOE Graduate conference, Kathmandu,Nepal, 2014.

[10] B. J. Flehinger, "Reliability Improvement through Redundancy at Various System Levels," IBM Journal of Research and Development, vol. 22, no. doi:10.1147/rd.22.0148 , pp. 148-158, 1958.

[11] B. N. S.P. Kaushish, "Silting Problems in Hydropower Plants," in A.A Balkema Publisher, Bangkok, Thailand, 2001.

[12] S. K. Shah and D. R. Shrestha, "Design Modification of Cooling Water System for Hydropower Plants [A Case Study of Middle Marsyangdi Hydropower Plant in Nepal]," Global Journal of Researches in Engineering: F Electrical and Electronics Engineering, vol. XV, no. VI, pp. 9-16, 2015.

[13] G. Gupta, R. Mishra and N. Mundra, "Development of a framework for Reliability centered Maintenance," in International conference on Industrial Engineering and Opeerations Management, Bandung, Indonesia, 2018. 